\title{
ResearchOnline@JCU
}

This is the author-created version of the following work:

Ban, Natalie C., Gurney, Georgina Grace, Marshall, Nadine A., Whitney, Charlotte K., Mills, Morena, Gelcich, Stefan, Bennett, Nathan J., Meehan, Mairi C., Butler, Caroline, Ban, Stephen, Tran, Tanya C., Cox, Michael E., and Breslow, Sara Jo (2019) Well-being outcomes of marine protected areas. Nature Sustainability, 2 pp. 524-532.

Access to this file is available from: https://researchonline.jcu.edu.au/59925/

Please refer to the original source for the final version of this work: 


\title{
Well-being outcomes of marine protected areas
}

\author{
Authors: Natalie C. Ban ${ }^{a *}$, Georgina Grace Gurney ${ }^{b}$, \\ Nadine A. Marshall ${ }^{\mathrm{c}}$, Charlotte K. Whitney ${ }^{\mathrm{a}}$, Morena Mills ${ }^{\mathrm{d}}$, \\ Stefan Gelcich ${ }^{\mathrm{e}}$, Nathan J. Bennett ${ }^{\mathrm{fgh} *}$, Mairi C. Meehani, \\ Caroline Butler', Stephen Ban ${ }^{\mathrm{k}}$, Tanya C. Tran ${ }^{\mathrm{a}}$, Michael E. \\ Cox', Sara Jo Breslow ${ }^{\mathrm{m}}$
}

a School of Environmental Studies, University of Victoria, PO Box 3060 STN CSC, Victoria, BC V8W3R4, Canada

${ }^{\mathrm{b}}$ ARC Centre of Excellence for Coral Reef Studies, James Cook University, Townsville, Queensland 4811, Australia

${ }^{\circ}$ CSIRO Land and Water, Townsville, Queensland, Australia

${ }^{\mathrm{d}}$ Department of Life Sciences, Imperial College London, Ascot, UK

e Center of Applied Ecology and Sustainability (CAPES) and Center for the Study of Multiple-

Drivers on Marine Socio-Ecological Systems, Pontificia Universidad Catolica de Chile,

Santiago, Chile

${ }^{f}$ Institute for Resources, Environment, and Sustainability, University of British Columbia,

Vancouver, British Columbia, Canada

${ }^{g}$ Center for Ocean Solutions, Stanford University, Stanford, CA, USA

${ }^{\mathrm{h}}$ FishMPABlue2 Project, University of Nice Sophia Antipolis, Nice, France

'Memorial University of Newfoundland, St. John's, Newfoundland, Canada

${ }^{j}$ Gitxaala Nation Fisheries Program, Prince Rupert, British Columbia, Canada

${ }^{\mathrm{k}}$ BC Parks, Ministry of Environment and Climate Change Strategy, Victoria, British Columbia, Canada

'Environmental Studies, Dartmouth College, Hanover, NH, USA

${ }^{m}$ EarthLab, University of Washington, Seattle, WA, USA

${ }^{*}$ Corresponding author

ACCEPTED AUTHOR MANUSCRIPT (Accepted final version of manuscript post peerreview but prior to publisher contributions such as copy-editing, formatting etc).

Nature Sustainability, vol. 2, pp. 524-532, June 2019 


\section{Well-being outcomes of marine protected areas}

3 Abstract

4 Marine protected areas are advocated as a key strategy for simultaneously protecting marine

5 biodiversity and supporting coastal livelihoods, but implementation can be challenging for

6 numerous reasons, including perceived negative effects on human well-being. We synthesized

7 research from 118 peer-reviewed articles that analyze outcomes related to marine protected

8 areas on people, and found that half of documented well-being outcomes were positive, and

9 about one-third were negative. No-take, well-enforced, and old marine protected areas had

10 positive human well-being outcomes, which aligns with most findings from ecological studies.

11 While on balance larger marine protected areas improved ecological conditions, smaller areas

12 improved human well-being. Most studies focused on economic and governance aspects of

13 well-being, leaving social, health, and cultural domains understudied. Well-being outcomes

14 arose from direct effects of marine protected area governance processes or management

15 actions, and from indirect effects mediated by changes in the ecosystem. Our findings illustrate

16 that both human well-being and biodiversity conservation can be improved through marine

17 protected areas, yet negative impacts commonly co-occur with benefits.

19 Main text

21 Many countries have committed to establishing $10 \%$ of their marine waters as marine protected

22 areas (MPAs) $)^{1,2}$ to stem biodiversity declines and safeguard related ecosystem services ${ }^{3,4}$.

23 While conservation effectiveness of MPAs has been demonstrated through ecological studies ${ }^{5,6}$,

24 many MPAs have social goals and outcomes that are less well understood ${ }^{7}$. Understanding how

25 human well-being may be affected by MPAs is important for ethical reasons with potential 
26 implications for biological outcomes. MPAs that support positive human well-being are also

27 more likely to achieve their conservation goals because they are more acceptable, desirable,

28 and supported by local communities ${ }^{8-10}$. This, in turn, can increase compliance ${ }^{11}$. Human well-

29 being is an important end goal, with co-benefits for conservation goals and policies (e.g. $\left.{ }^{12-15}\right)$.

30 Ensuring that positive human well-being outcomes are associated with implementation and

31 maintenance of MPAs is thus important for acceptance and effectiveness.

33 Worldwide, increasing establishment of MPAs ${ }^{16}$ has stimulated research on well-being

34 outcomes of MPAs, with a substantial increase in studies in the last decade (Figure S1). The

35 most recent synthesis of impacts of MPAs on human well-being (hereafter "well-being

36 outcomes"), published a decade ago, focused only on fishing communities due to data

37 constraints ${ }^{7}$. That study found that MPA establishment tends to improve food security and

38 empower local fishing communities, but that effects vary depending on the social and

39 governance context ${ }^{7,17}$. Since this synthesis was conducted, there have been numerous case

40 studies (Supplementary References) that document a broad array of positive and negative

41 social outcomes from MPAs. Given the commitment by countries to establish MPAs ${ }^{16}$,

42 understanding their effects on well-being outcomes is crucial.

43

44 We performed a systematic literature review on the well-being outcomes of MPAs (Tables S1, 45 S2). We examined social, health, culture, economic, and governance domains of human well46 being $^{18}$, and added an environment domain since environmental health is fundamental to 47 human well-being and vice versa (Table S1). Governance as a well-being outcome refers to the 48 experience of local people with the quality of governance processes - including actors such as 49 empowerment, participation, conflict management and accountability ${ }^{19}$. Our analysis allows us 50 to answer questions critical for assessing well-being outcomes of MPAs. Where and how are 51 well-being outcomes of MPAs studied? What domains of human well-being are included in 
52 scientific studies? Are well-being outcomes consistent across different groups of people (i.e.

53 stakeholders)? What factors influence whether positive or negative outcomes are perceived or

54 experienced? Finally, what well-being outcomes co-occur?

Data on human well-being outcomes of MPAs

58 We identified 118 peer-reviewed articles (Supplementary References, Figure S1) that

59 investigated an existing MPA or MPAs, and included information about the measured or

60 perceived impact(s) of the MPA(s) on people (108 articles with quantitative or directional data).

61 The relevant articles studied 121 MPAs distributed globally (Figure 1a), containing 267

62 observations of stakeholders (i.e., some articles studied multiple stakeholders, as defined in the

63 source paper), each of which described one or more well-being outcomes of MPAs (i.e., 606

64 data points of well-being outcomes). Coastal communities referred to residents in coastal towns

65 rather than more specific groups such as fisheries or tourism, and recreation was defined as

66 non-extractive personal activities (e.g., diving, kayaking). $75 \%$ of stakeholder data involved

67 fisheries; of those, $76 \%$ were about artisanal and small-scale fisheries, $15 \%$ about industrial

68 fisheries, and $9 \%$ about recreational fisheries, but the sample sizes were too small to analyze by

69 disaggregated fisheries categories. Further disaggregation, while not provided in the papers,

70 might highlight additional biases in studies (e.g., gender, ethnicity) ${ }^{20}$. Most MPAs with relevant

71 data were from Asia (especially the Philippines) and Europe, with a fairly even distribution of

72 MPA size and age categories. The most common types of MPA governance were state-led and

73 community-based, followed by co-managed. Several study designs were used, with those

74 asking stakeholders for their perceptions of social change being the most common, followed by

75 studies before and after MPA establishment, and studies using control-impact design (e.g.,

76 inside and outside of MPAs). The least common study type was the before-after control-impact

77 design (Figure 1b). 


\section{Domains of human well-being considered in MPA studies}

81 All domains of well-being were mentioned at least once in every paper, whether as the focus of 82 study, or in the discussion (Figure 2). Economic, governance and environment categories were 83 most prevalent, often the focus of assessment. Social, health, and cultural domains received

84 much less attention, usually in the form of a cursory mention in the discussion. The category 85 mentioned most frequently was economic livelihoods, in which we included fisheries catches

86 and catch per unit effort (CPUE). Categories of cultural diversity and mental health received the

87 least attention. We posit that the uneven consideration of categories is due to a combination of

88 the societal importance placed on economic outcomes, and the challenges in measuring social,

89 health, and cultural domains. Ten variables across four domains had enough quantitative

90 information to be further analyzed for outcomes (Figure 3): income, number of users, CPUE,

91 catches, cost of activity (only mentioned in relation to fishing regarding increasing fuel costs

92 when distance to fishing grounds increased), stakeholder rights to inform resource management

93 (hereafter "resource control"), stakeholder support for the MPA, change in spatial use patterns

94 (hereafter "spatial change"), conflict, and community involvement (Table S1).

\section{Well-being outcomes of MPAs}

98 Overall, there were more positive (51\%) than negative (31\%) well-being outcomes reported in 99 the literature (Figure 3, Table S3). Shifts in the numbers of users differed between stakeholder 100 groups, with more increases for tourism and recreation, and more decreases for fisheries (Table 101 S4). The most positive well-being outcomes of MPAs related to community involvement $(76 \%$ 102 positive), CPUE (73\%), and income (65\%). The most negative outcomes manifested through 103 increasing costs of activities (100\%, though only 13 instances, all related to increased cost of 
104 fishing), and conflict (79\%). We interpreted increased conflict as a negative well-being outcome,

105 although conflict is not necessarily negative. Debate and to some extent, conflict, is recognized

106 as a critical element of democratic governance and procedural justice ${ }^{21}$, often providing space

107 for a diversity of voices, including those of minority groups ${ }^{22}$. The most ambiguous outcomes

108 (i.e., no change, or could not be interpreted as negatively or positively affecting people)

109 occurred with shifting spatial usage patterns - mostly of fishing activities - due to the MPA.

111 Some explanatory variables had a significant influence on well-being outcomes (Figure 4, Table

112 S5). MPAs that were single zones, no-take, old, and had high enforcement, indicated more

113 positive well-being outcomes than other categories (Fisher's exact tests and ANOVAs, p-value

$114<0.05)$. Study design was also correlated with outcomes, with studies that ascertained

115 stakeholders' perceptions (that did not fall into the other research design categories) more

116 negative than those that objectively measured outcomes. While the data showed that positive

117 well-being outcomes were more prevalent in tropical systems, the correlation was not

118 statistically significant when considering combined outcomes (Figure 4, Table S5). When

119 analyzing specific outcomes (e.g., income, CPUE, number of users, etc.; Table S6), some

120 additional patterns emerged. Ecosystem type was correlated with income, CPUE, support,

121 spatial change, and community involvement; no-take zone presence was correlated with

122 income, support, and community involvement; and compliance was correlated with resource

123 control, support, spatial change, and conflict; for additional correlations, see Table S6. However,

124 sample sizes were small when disaggregating outcomes, because most studies only included

125 one or two outcomes.

126

127 Co-occurrences of outcomes showed some interesting and unexpected patterns (Figure 5). As

128 expected, an increase in catches correlated with an increase in CPUE. When catches

129 increased, there was also more conflict (which we interpreted as negative), perhaps due to 
uneven distribution of benefits. Some co-occurrences, despite showing significant trends, have

131 small sample sizes and are thus difficult to interpret (catches and income; catches and number

132 of users; Figure 5), and we emphasize that correlation does not mean causation.

134 Discussion

136 Our finding that MPAs have more positive than negative well-being outcomes across diverse 137 stakeholder groups - similar to findings by Mascia, et al. ${ }^{7}$ for fishers - lends credibility to the 138 potential of MPAs to benefit both biodiversity and people. Research shows that ecologically 139 effective MPAs require five key attributes: no-take, well enforced, old (>10 years), large

$140\left(>100 \mathrm{~km}^{2}\right)$, and isolated ${ }^{5}$. Similarly, we found that no-take, well enforced, and old MPAs also led 141 to more positive well-being outcomes. However, our results indicate that small MPAs had more 142 positive well-being outcomes than large MPAs. Certain aspects of MPA design and 143 management may thus contribute to both positive ecological and well-being outcomes, whereas 144 others will require trade-offs. Our findings also highlight that there are both co-benefits and 145 trade-offs among stakeholder groups, leading to questions of equity, justice, and power.

147 The scientific literature on well-being outcomes of MPAs focused on relatively few indicators 148 mostly within the economic domain, such as income earned or catches, whereas many other 149 potentially relevant indicators in other domains were mentioned but rarely measured (see Table 150 S1 for examples of indicator topics for all well-being categories). For instance, indicators of diet 151 and food availability can reveal changes in health of local populations dependent on coastal 152 resources. The fact that measurements relate to only a few well-being outcomes is important, 153 because there is a risk that easily quantifiable indicators come to dominate the discourse about 154 well-being outcomes of MPAs. Multidimensional aspects of well-being, notably in relation to 155 values, are particularly difficult to quantify (e.g. power, sense of community), but can have 
156 important implications for the acceptance and support of MPAs ${ }^{17,23}$. Without being readily

157 measurable, there is a danger these aspects of human well-being may inadvertently disappear

158 from the problem/decision-making context because they are not being measured or reported if

159 decision-makers are not part of the affected communities (e.g., state managed MPAs).

160 Furthermore, indicators can become self-perpetuating, with the rationale for using indicators

161 based on past studies. Indeed, we justified some of the indicators we quantified because they

162 were assessed in a previous study ${ }^{7}$. Some indicators that are easily measured, such as equity

163 (e.g., examining outcomes by race, gender, age, location, cultural group, etc.), are rarely

164 included. Thus, we encourage those studying the well-being outcomes of MPAs to combine

165 previously tested indicators (see Hicks, et al. ${ }^{24}$ ) with efforts to develop a broader set of

166 indicators that represent holistic domains of human well-being ${ }^{18,25,26}$. Furthermore, qualitative

167 studies are particularly important in providing explanation and context for indicators, which alone

168 cannot tell the full story ${ }^{25,27}$.

169

170 While social scientists are increasingly called on to assess human well-being outcomes of

$171 \mathrm{MPAs}^{28}, \mathrm{MPA}$ development and management continues to be primarily occurring without

172 consistent quantitative or qualitative monitoring of well-being outcomes ${ }^{29,30}$. We need to move

173 towards ensuring the long-term well-being of people and communities that depend on marine

174 systems, and develop appropriate studies and indicators to capture the multi-dimensional

175 outcomes of MPAs. Similarly, participatory processes are critical to ensure that those affected

176 by MPAs are involved in making management decisions. Social sciences can provide important

177 methodological and analytical insights for qualitative studies and quantitative monitoring,

178 regarding ways in which stakeholders frame MPAs in their own terms, and how MPAs are

179 continually mediated through cultural values and worldviews, media discourses, and perceived

180 trust in science and institutions. A shift within management agencies is starting to occur, as

181 exemplified by the recent management focus on diverse ecological and cultural values ${ }^{31,32}$. 
183 The process of creating MPAs, that are small, local, and managed by communities, has

184 numerous benefits for human empowerment and well-being, notwithstanding environmental 185 outcomes ${ }^{33-35}$. Two main mechanisms for well-being outcomes of MPAs were reflected in the 186 literature: (1) direct effects of MPA governance processes or management actions; and (2) 187 indirect effects mediated by changes in the ecosystem. Direct effects included, for example, 188 conflicts arising during MPA planning processes, community involvement in management, 189 enhancement or displacement of livelihoods, and limitations on access rights (e.g., 190 displacement from fishing an area, or exclusive access for some users). Indirect effects of 191 MPAs on well-being are generally due to recovering marine systems and included increases in 192 catches, CPUE, and income from resource extraction. These indirect effects are influenced by 193 the state and management of ecosystems surrounding the MPA ${ }^{36}$. Some aspects of well-being 194 outcomes may arise with both mechanisms. For instance, conflict can be caused by stakeholder 195 discussions during MPA establishment and management fora, and it can also result from new or 196 shifting user groups in the area, or changing availability of resources.

198 We found that conflict increased more often than decreased with MPA implementation. A key 199 source of conflict identified in the reviewed literature related the reconfiguration of stakeholders' 200 resource access, use and rights as a result of MPA implementation. For example, conflict was 201 often related to MPA-mediated displacement of users that increased overlap in the use of 202 marine areas. This was particularly common amongst fishers employing different gear types 203 (e.g., ${ }^{37,38}$ ). Further, conflict was often documented in relation to MPA decision-making 204 processes during which different stakeholder groups vie for influence and control. In many 205 cases, this conflict occurred between local users (often fishers) and external stakeholders, 206 including conservation organizations (e.g., ${ }^{39}$ ) and tourism operators (e.g. ${ }^{40}$ ). Given the power 207 differentials between local users and external stakeholders (particularly in Global South 
contexts), such processes were often documented as further marginalizing local users and

209 contributing to inequities in resource use or access ${ }^{41}$. However, in some cases it was reported

210 that MPA establishment was seen as a negotiation opportunity for local users to acquire or

211 solidify their rights over a marine area. For example, Cudney-Bueno et al. ${ }^{42}$ report although

212 there was substantial conflict over the granting of access rights during MPA implementation,

213 fishers territorial access rights were strengthened through the process. Further, conflict can

214 denote debate and deliberative decision-making, essential to democratic governance and

215 procedural justice ${ }^{35}$. For example, Gurney et al. ${ }^{41}$ document how conflict led to improved

216 governance, whereby MPA management group members fished together in an MPA to highlight

217 lax enforcement by government officials.

219 Given that MPA processes involve reconfiguring resource use and access, and typically involve 220 a number of competing stakeholder groups, conflict is likely ${ }^{43}$. Conflict also highlights that there

221 are commonly trade-offs among different people in MPA design and management, and that win222 win situations are rare and difficult to negotiate. Better understanding the nuances of conflict, 223 and managing expectations, might help inform and innovate future MPA design and 224 management processes. Collaboration between resource-users may also provide opportunities 225 for dialogue, sense-making and conflict resolution ${ }^{44}$. Involving the community at initial phases in 226 the policy decision-making process can promote deliberation and increase the efficiency in 227 producing workable outcomes ${ }^{45,46}$. However, we need to recognize that access to power is 228 uneven among stakeholders.

230 An interesting finding was that the design of studies affected whether well-being outcomes 231 appeared more positive or negative. Studies that measured the perceptions of stakeholders 232 (e.g., their self-assessment of impacts through surveys) were more negative than those that 233 attempted to measure objective aspects of human well-being (e.g., tracking fisheries landings 
234 before and after MPA implementation). Such a discrepancy could be due to who is measuring 235 the outcome (stakeholders vs. researchers). Also, different aspects of well-being are captured 236 by subjective and objective measures, with objective measures less able to capture some 237 aspects of well-being that critically affect people, such as culture, conflict, and social relations.

238 Subjective measures do not only reflect perception; they can also be self-reports of observed 239 reality. Perceptions and self-reports clearly matter in their own right, because these can lead to 240 support for, or opposition to, conservation ${ }^{19,47,48}$. Thus using both objective and subjective 241 measures is essential, as they can test and lend validity to each other. Understanding why 242 results of objective measures are sometimes inconsistent with reported perceptions may help 243 identify more acceptable and robust management actions ${ }^{49}$.

245 Our review revealed several research gaps that require attention. Some systems (e.g., Arctic, 246 sub-tropical) had no or very little data, and some regions (e.g., South America) and stakeholder 247 groups (e.g., recreational users) were understudied. A methodological gap was that the most 248 powerful study design - before-after-control-impact ${ }^{50}$ - was also the least prevalent.

249 Furthermore, studies to date predominantly concerned single MPAs. As MPA networks are 250 being established, there is a need to think about assessing well-being outcomes at the scale of 251 networks, rather than single sites, which requires attention to potential mismatches between 252 ecological and social systems. Some limitations of our research are that we do not know 253 whether MPAs that have been studied are biased towards positive or negative results. We also 254 considered all indicators of well-being as important, whereas in reality some aspects will be 255 more important to stakeholders, and this will likely vary by stakeholder group. A more nuanced 256 understanding of human well-being outcomes of MPAs is critical for creating management 257 measures that benefit people and ecosystems. 
259 Acknowledgements: N.C.B. hosted a workshop of co-authors that was made possible by her

260 Lansdowne Scholar Award from the University of Victoria, and the OceanCanada SSHRC

261 Partnership. N.J.B. also recognized the OceanCanada Partnership, G.G.G. recognizes funding

262 from the Australian Research Council, C.K.W. recognizes support from an NSERC Canada

263 Graduate Scholarship.

264

265 Author contributions: N.C.B. conceived of the idea, reviewed the literature, led study design, 266 collated quantitative data, carried out analyses, and drafted the paper. All authors contributed 267 ideas and to study design, reviewed papers for qualitative information, and edited the paper.

268 C.W. and T.T. reviewed the quantitative data.

269 
2711 Convention on Biological Diversity. Aichi Biodiversity Targets, 2010).

2722 United Nations. Transforming Our World: The 2030 Agenda for Sustainable

273

274

275

276

277

278

279

280

281

282

283

284

285

286

287

288

289

290

291

292

293

294

295

296

297

298

299

300

301

302

303

304

305

306

307

308

309

310

3 Jones, K. R. et al. The location and protection status of Earth's diminishing marine wilderness. Curr. Biol. 28, 2506-2512.e2503 (2018).

4 Halpern, B. S. et al. Spatial and temporal changes in cumulative human impacts on the world's ocean. Nat Commun 6, Article no. 7615, doi:10.1038/ncomms8615 (2015).

5 Edgar, G. J. et al. Global conservation outcomes depend on marine protected areas with five key features. Nature 506, 216-220, doi:10.1038/nature13022 (2014).

6 Lester, S. E. et al. Biological effects within no-take marine reserves: a global synthesis. Marine Ecology-Progress Series 384, 33-46, doi:10.3354/meps08029 (2009).

7 Mascia, M. B., Claus, C. \& Naidoo, R. Impacts of Marine Protected Areas on Fishing Communities. Conservation Biology 24, 1424-1429, doi:http://dx.doi.org/10.1111//.15231739.2010.01523.x (2010).

8 Chaigneau, T. \& Brown, K. Challenging the win-win discourse on conservation and development: analyzing support for marine protected areas. Ecology and Society 21 (2016).

9 Diedrich, A., Stoeckl, N., Gurney, G. G., Esparon, M. \& Pollnac, R. Social capital as a key determinant of perceived benefits of community-based marine protected areas. Conservation biology 31, 311-321 (2017).

10 Gurney, G. G. et al. Participation in devolved commons management: Multiscale socioeconomic factors related to individuals' participation in community-based management of marine protected areas in Indonesia. Environmental Science \& Policy 61, 212-220, doi:http://dx.doi.org/10.1016/j.envsci.2016.04.015 (2016).

11 Arias, A., Cinner, J. E., Jones, R. E. \& Pressey, R. L. Levels and drivers of fishers' compliance with marine protected areas. Ecology and Society 20 (2015).

12 Guidetti, P., Bussotti, S., Pizzolante, F. \& Ciccolella, A. Assessing the potential of an artisanal fishing co-management in the Marine Protected Area of Torre Guaceto (southern Adriatic Sea, SE Italy). Fisheries Research 101, 180-187, doi:10.1016/j.fishres.2009.10.006 (2010).

13 Gelcich, S., Godoy, N., Castilla, J. C. J. O. \& Management, C. Artisanal fishers' perceptions regarding coastal co-management policies in Chile and their potentials to scale-up marine biodiversity conservation. 52, 424-432 (2009).

14 Jenkins, A., Horwitz, P. \& Arabena, K. J. E. C. My island home: place-based integration of conservation and public health in Oceania. 45, 125-136 (2018).

15 Pollnac, R. et al. Marine reserves as linked social-ecological systems. Proceedings of the National Academy of Sciences, USA 107, 18262-18265 (2010).

16 Sala, E. et al. Assessing real progress towards effective ocean protection. Marine Policy 91, 11-13 (2018).

17 Jones, P. Equity, justice and power issues raised by no-take marine protected area proposals. Marine Policy 33, 759-765 (2009).

18 Kaplan-Hallam, M. \& Bennett, N. J. Adaptive social impact management for conservation and environmental management. Conservation Biology 32, 304-314 (2018).

19 Bennett, N. J. et al. Local support for conservation is associated with perceptions of good governance, social impacts and ecological effectiveness. Conservation Letters (In press).

20 Gurney, G. G., Pressey, R. L., Cinner, J. E., Pollnac, R. \& Campbell, S. J. Integrated conservation and development: evaluating a community-based marine protected area 
project for equality of socioeconomic impacts. Philosophical Transactions of the Royal Society B: Biological Sciences 370, doi:10.1098/rstb.2014.0277 (2015).

21 Matulis, B. S. \& Moyer, J. R. Beyond Inclusive Conservation: The Value of Pluralism, the Need for Agonism, and the Case for Social Instrumentalism. Conservation Letters 10, 279-287, doi:10.1111/conl.12281 (2016).

22 Mouffe, C. Deliberative democracy or agonistic pluralism? Social Research 66, 745-758 (1999).

23 Hill, L. S., Johnson, J. A. \& Adamowski, J. Meeting Aichi Target 11: Equity considerations in Marine Protected Areas design. Ocean \& Coastal Management 134, 112-119, doi:https://doi.org/10.1016/j.ocecoaman.2016.09.017 (2016).

24 Hicks, C. C. et al. Engage key social concepts for sustainability. Science 352, 38, doi:10.1126/science.aad4977 (2016).

25 Breslow, S. J. et al. Conceptualizing and operationalizing human wellbeing for ecosystem assessment and management. Environmental Science \& Policy 66, 250-259 (2016).

26 McKinnon, M. C. et al. What are the effects of nature conservation on human wellbeing? A systematic map of empirical evidence from developing countries. 5, 8 (2016).

27 Charnley, S. et al. Evaluating the best available social science for natural resource management decision-making. 73, 80-88 (2017).

28 Pascal, N. et al. Evidence of economic benefits for public investment in MPAs. Ecosystem Services 30, 3-13 (2018).

29 Álvarez-Romero, J. G. et al. Research advances and gaps in marine planning: towards a global database in systematic conservation planning. Biological Conservation, doi:https://doi.org/10.1016/j.biocon.2018.06.027 (2018).

30 Fox, H. E. et al. How are our MPAs doing? Challenges in assessing global patterns in marine protected area performance. Coastal Management 42, 207-226 (2014).

31 Fox, H. E. et al. Reexamining the science of marine protected areas: linking knowledge to action. Conservation Letters 5, 1-10, doi:10.1111/j.1755-263X.2011.00207.x (2012).

32 Twichell, J., Pollnac, R. \& Christie, P. Lessons from Philippines MPA Management: Social ecological interactions, participation, and MPA performance. Environmental management 61, 916-927 (2018).

33 Christie, P., White, A. \& Deguit, E. Starting point or solution? Community-based marine protected areas in the Philippines. Journal of Environmental Management 66, 441-454 (2002).

34 Gelcich, S. et al. Alternative strategies for scaling up marine coastal biodiversity conservation in Chile. Maritime Studies 14, 5, doi:10.1186/s40152-015-0022-0 (2015).

35 Jupiter, S. D., Cohen, P. J., Weeks, R., Tawake, A. \& Govan, H. Locally-managed marine areas: multiple objectives and diverse strategies. Pacific Conservation Biology 20, 165-179 (2014).

36 Halpern, B. S. \& Warner, R. R. Marine reserves have rapid and lasting effects. Ecol. Lett. 5, 361-366 (2002).

37 Suuronen, P., Jounela, P. \& Tschernij, V. Fishermen responses on marine protected areas in the Baltic cod fishery. Marine Policy 34, 237-243, doi:10.1016/j.marpol.2009.07.001 (2010).

38 Hattam, C. E., Mangi, S. C., Gall, S. C. \& Rodwell, L. D. Social impacts of a temperate fisheries closure: understanding stakeholders' views. Marine Policy 45, 269-278, doi:http://dx.doi.org/10.1016/i.marpol.2013.09.005 (2014).

39 Yang, Y.-C., Wang, H.-Z. \& Chang, S.-K. Social Dimensions in the Success of a Marine Protected Area: A Case in a Taiwan Fishing Community. Coastal Management 41, 161 (2013). 
40 Oracion, E. G., Miller, M. L. \& Christie, P. Marine protected areas for whom? Fisheries, tourism, and solidarity in a Philippine community. Ocean \& Coastal Management 48, 393-410, doi:http://dx.doi.org/10.1016/j.ocecoaman.2005.04.013 (2005). Gurney, G. G. et al. Poverty and protected areas: An evaluation of a marine integrated conservation and development project in Indonesia. Global Environmental Change 26, 98-107, doi:https://doi.org/10.1016/i.gloenvcha.2014.04.003 (2014).

42 Cudney-Bueno, R. et al. Governance and effects of marine reserves in the Gulf of California, Mexico. Ocean \& Coastal Management 52, 207-218 (2009).

43 Buchy, M. \& Race, D. The twists and turns of community participation in natural resource management in Australia: What is missing? Journal of environmental planning and management 44, 293-308 (2001).

44 Källström, H. N. \& Ljung, M. Social sustainability and collaborative learning. AMBIO: A Journal of the Human Environment 34, 376-382 (2005).

45 Bruckmeier, K. Interdisciplinary conflict analysis and conflict mitigation in local resource management. Ambio, 65-73 (2005).

46 Le Tissier, M., Hills, J., McGregor, J. \& Ireland, M. A training framework for

47 McNeill, A., Clifton, J. \& Harvey, E. S. Attitudes to a marine protected area are associated with perceived social impacts. Marine Policy 94, 106-118, doi:https://doi.org/10.1016/j.marpol.2018.04.020 (2018).

48 Bennett, N. J. Using perceptions as evidence to improve conservation and environmental management. Conservation Biology 30, 582-592, doi:10.1111/cobi.12681 (2016).

49 Elwell, T. L., Gelcich, S., Gaines, S. D. \& López-Carr, D. Using people's perceptions of ecosystem services to guide modeling and management efforts. Sci. Total Environ. 637, 1014-1025 (2018).

50 Underwood, A. On beyond BACl: sampling designs that might reliably detect environmental disturbances. Ecological applications 4, 3-15 (1994). 
Figure 1. (a) Global distribution of the number of studies of MPAs by country included in the analysis, with MPAs shown in pink outline. (b) Characteristics of the studies and MPAs included

402 in this review. Numbers in parentheses indicate the number of studies (i.e., papers) for study 403 design (out of 118), and the number of MPAs (out of a possible 121; some MPAs had no data 404 about some characteristics). BACl stands for before-after control-impact; S., C., and N. stand for 405 South, Central, and North, respectively; co-mgnt is an abbreviation of co-managed.

Figure 2. Domains and categories of human well-being mentioned in studies reviewed. Env.

408 means environmental. For the rationale underpinning our categorization scheme, see ${ }^{18}$.Table

409 S1 describes details about the domains of human well-being

411 Figure 3. Summary of well-being outcomes of MPAs. See Table S3 for interpretations of 412 negative, positive, and ambiguous outcomes. Sums of percentages may not add up to $100 \%$ 413 due to rounding errors. "Com. involvement" refers to community involvement. \% refers to the 414 percentage of data point that were positive, negative, or ambiguous (neither clearly positive or 415 negative; or no change). Data points consist of all measures of well-being by stakeholder 416 group(s) contained in the papers reviewed. See Table S3 for interpretation of positive, negative, 417 and ambiguous.

419 Figure 4. Combined well-being outcomes summarized by explanatory variables. See Table S3 420 for interpretations of negative, positive, and ambiguous outcomes. Sums of percentages may 421 not add up to $100 \%$ due to rounding errors. Ambiguous refers to no change or unclear 422 directionality of change. Bolded variables are those that show significant $(p<0.05)$ correlations 423 (Fisher's exact tests or ANOVAs) between the variable and synthesized outcomes (Table S5). 424 For analyses by disaggregated outcomes, see Table S6. 
426 Figure 5. Co-occurrence of select well-being outcome variables. Blue circles are scaled relative 427 to each plot to illustrate the sample size (number inside the circle) of co-occurrences, and the 428 grey bars indicate the sample sizes of the rows and columns. The first variable stated is shown 429 on the $x$-axis, and the second on the $y$-axis. ${ }^{* *}$ indicates Fisher's exact test $p<0.05,{ }^{*} p<0.1$. 430 
3 Selecting papers: We carried out a systematic literature review in Web of Science (capturing all dates,

4 with the first article appearing in 1973, last searched on 5 June 2018; Table S1) to identify studies that

5 assessed the outcomes of MPAs on human well-being (hereafter well-being outcomes). We included

6 original peer-reviewed journal articles that investigated (1) an existing MPA or MPAs, (2) included

7 information about the measured or perceived impact(s) of the MPA(s) on people. Excluded were studies

8 about: the impact of users on the MPA; opinion papers; modelling studies with hypothetical or

9 predictive data; anticipated impacts; descriptive studies of fishing/tourism effort within an MPA without

10 a temporal comparison; and review papers. Papers included the following research designs: before-after

11 studies; control-impact (or inside-outside) comparisons; before-after-control-impact (BACI) studies;

12 distance from MPAs; studies that assessed people's perceptions that did not fit in the other categories;

13 and other (e.g., historical narratives, ethnographic studies).

15 Qualitative data and analyses on human well-being: We reviewed papers that met our selection criteria

16 for mentions of possible well-being outcomes (i.e., qualitative information). We tracked the indicators or

17 phrases mentioned, and summarized them into slightly adapted domains and categories of human well-

18 being reported by Kaplan-Hallam and Bennett ${ }^{1}$ (Table S1). We used this categorization because it

19 provided a recent review and synthesis of social impacts in conservation and environmental

20 management and was therefore highly relevant to our study. It synthesizes several related relevant

21 frameworks, which we also considered e.g., ${ }^{2-6}$. Our modifications were to add 'environment' as a

22 domain to encompass variables relating directly to the ecological system (although we did not track

23 quantitative data for this domain); and we added 'legitimacy' to governance domain as this is an 
24 important component of governance ${ }^{7}$. Ambiguities between domains of well-being meant that some

25 indicators could fit within multiple domains, so we made a decision about the best fit. For example,

26 'number of users' can represent the cultural engagement with an activity, and we associated it with the

27 cultural domain. It could also be an indicator of economic outcomes. We graphed the number of papers

28 mentioning each of the domains and categories to provide an overview of the prevalence for different

29 aspects of human well-being.

31 Quantitative data on human well-being: We collated results of measurements (quantitative data) of the

32 well-being outcomes of MPAs by the most refined yet independent stakeholder group possible, such

33 that a paper could provide multiple data points relating to different levels and types of social

34 aggregation (e.g., by village, and/or by stakeholder type, and/or fishing gear type). We collated data for

35 variables known to be important, and that are commonly measured, as identified by Mascia, et al. ${ }^{8}$ :

36 number of users (e.g., number of fishers, number of tourism operators), community organization (i.e.,

37 number of active civil society organizations exclusively or primarily of that stakeholder group), income,

38 and the fisheries-specific measure of catch per unit effort (CPUE). In addition, we tracked other variables

39 that were commonly measured within the papers reviewed: resource control (i.e., involvement by

40 stakeholders in governing natural resources within the MPA), support for the MPA, cost of carrying out

41 an activity (e.g., fuel costs for fishers or tourism operators), conflict, spatial usage change of the MPA

42 (i.e., whether and how spatial usage patterns changed, mostly relating to fishing), and fisheries-specific

43 total catches. We obtained quantitative data from the results of the papers, and tables and figures

44 therein, using WebPlotDigitizer (https://apps.automeris.io/wpd/) to acquire data from figures or graphs.

45 When multiple years were tracked, we used data from the latest year (i.e., longest time since

46 protection). When multiple species were included (e.g., CPUE for multiple species), we used the data for

47 the species with the most catches. Given papers used different methods and measures that are not 
comparable across contexts, we categorized data as increased, no change, or decreased. Some papers reported different outcomes for a single category of well-being (support: high or increased, medium or no change, low or decreased; spatial change: displacement; fishing the line; changed pattern; no change). Therefore, we interpreted these measures as illustrating predominantly positive outcomes, negative outcomes, or ambiguous outcomes (Table S3). We created a summary of the outcomes by stakeholder-MPA combinations, categorizing them as positive if only positive outcomes were found for a stakeholder group, negative if only negative outcomes existed, and tradeoff if both were described for a stakeholder group; we did not consider ambiguous outcomes in this summary. that might contribute to the well-being outcome of MPAs on people including characteristics of: the

Data on explanatory variables: We collated information provided in the papers about potential variables MPAs (country, continent, size, age), governance (community-based, co-managed, state- or NGOmanaged), management (no-take or multiple use), ecosystem protected (tropical, sub-tropical, temperate). We also included the study design used in the source papers (before-after, control-impact, $\mathrm{BACl}$, perception, distance from MPA, other). For the sake of visual comparisons, we classified size and age into three categories: small $(<1 \mathrm{~km} 2)$, medium $(1-100 \mathrm{~km} 2)$, and large $(>100 \mathrm{~km} 2) ;$ and young $(<5$ years), medium (5-10 years), and old (>10 years), respectively. Where details about the MPAs were lacking, we looked up the MPA on protectedplanet.net or MPA Atlas to ascertain the size and age. Some MPAs were not listed and thus had incomplete information. To estimate the age of the MPA at the time of the study, we used the designation date and the year the study was performed. If date of data collection was not provided, we assumed data were collected the year before publication. For MPAs that have had major management changes, we used the date of the change to calculate the age, not the original MPA designation date. Similarly, when papers mentioned that implementation (i.e., management plan) was different from the date of designation, we used the date of implementation. We 
72 categorized the stakeholder groups studied (fisheries, coastal communities, tourism, recreation, other).

73 Where the studies provided the data, we also compiled whether the MPAs had high enforcement (yes,

74 no), high compliance (yes, no), and clear boundaries (yes, no).

76 Quantitative analyses: We summarized the data by calculating the percentage of positive, ambiguous,

77 negative outcomes for the categories of human well-being that had quantitative data (economic,

78 governance, social, cultural). Similarly, we summarized the percentage of positive, ambiguous, and

79 negative outcomes by stakeholder group, ecosystems, MPA characteristics, MPA locations, governance,

80 and study design. We used Fisher's exact tests (2-tailed, for factor variables) and ANOVAs with Tukey

81 HSD post-hoc test (for continuous variables, size and age) to assess the statistical significance of the

82 relationship between synthesized outcomes (positive, trade-off, negative) and the explanatory variables.

83 We also examined within categories or variables with more than two categories, but these analyses did

84 not yield any additional insights. We used Microsoft Excel and R to visualize data, and all quantitative 85 analyses were carried out in $\mathrm{R}^{9}$.

87 We used balloon plots (in R package gplots ${ }^{10}$ ) and Fisher's exact tests to gauge co-occurrence of specific outcomes. We examined co-occurrence of economic indicators by comparing the variable with the most

89 data (catches, $n=124$ ) to other economic variables (income, number of users, CPUE), and the two next most commonly found variables to each other (CPUE and number of users). We excluded cost of activity

91 because of limited data points $(n=13)$. We then repeated the analyses comparing catches to governance

92 variables (resource control, support, spatial change) and social variables (conflict, community

93 involvement). Small sample sizes precluded statistical analyses with multiple variables. 
The data that support the findings of this study are available as supplementary materials.

\section{Methods references}

981 Kaplan-Hallam, M. \& Bennett, N. J. Adaptive social impact management for conservation and

99 environmental management. Conservation Biology 32, 304-314 (2018).

1002 Pomeroy, R. S., Parks, J. E. \& Watson, L. M. How is your MPA doing? A guidebook of natural and 101 social indicators for evaluating marine protected area management effectiveness. (IUCN, Gland, $102 \quad$ Switzerland, and Cambridge, UK, 2004).

1033 Mascia, M. B. \& Claus, C. A. A Property Rights Approach to Understanding Human Displacement

104

105

106

107

108

109

110

111

112

113 from Protected Areas: the Case of Marine Protected Areas. Conservation Biology 23, 16-23, doi:10.1111/j.1523-1739.2008.01050.x (2009).

4 Leisher, C., Samberg, L. H., Van Buekering, P. \& Sanjayan, M. Focal areas for measuring the human well-being impacts of a conservation initiative. Sustainability 5, 997-1010 (2013).

5 Biedenweg, K., Stiles, K. \& Wellman, K. A holistic framework for identifying human wellbeing indicators for marine policy. Marine Policy 64, 31-37 (2016).

6 Breslow, S. J. et al. Conceptualizing and operationalizing human wellbeing for ecosystem assessment and management. Environmental Science \& Policy 66, 250-259 (2016).

7 Adger, W. N. et al. Governance for sustainability: towards a 'thick' analysis of environmental decision-making. Environment and planning A 35, 1095-1110 (2003).

8 Mascia, M. B., Claus, C. A. \& Naidoo, R. Impacts of marine protected areas on fishing communities. Conservation Biology 24, 1424-1429, doi:doi: 10.1111/j.1523-1739.2010.01523.x (2010).

9 R Core Team. R: A language and environment for statistical computing. (R Foundation for Statistical Computing, Vienna, Austria, 2018).

10 Warnes, G. R. et al. Various R Programming Tools for Plotting Data. (https://cran.rproject.org/web/packages/gplots/gplots.pdf, Online, 2016). 
(a)

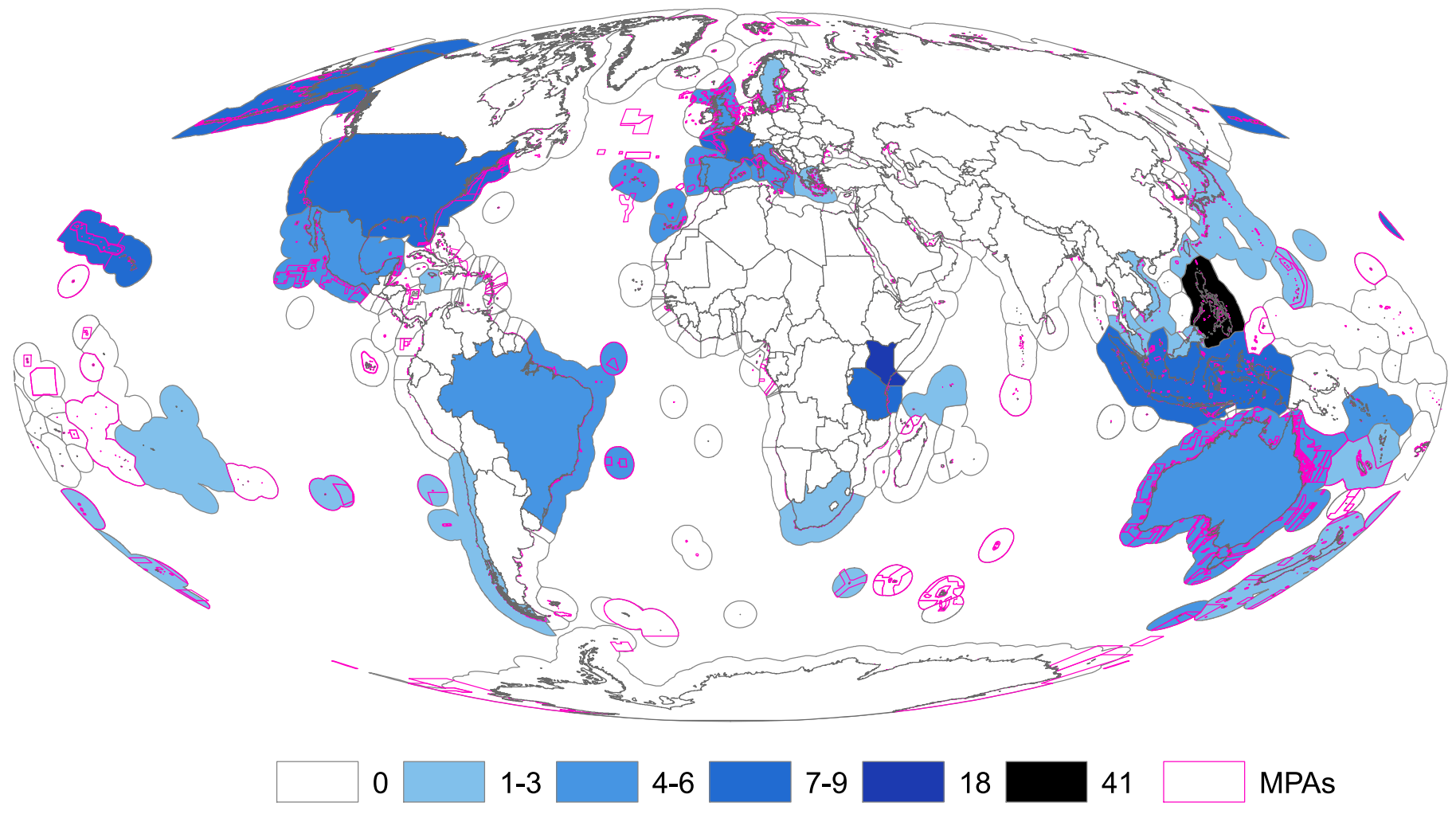

(b)

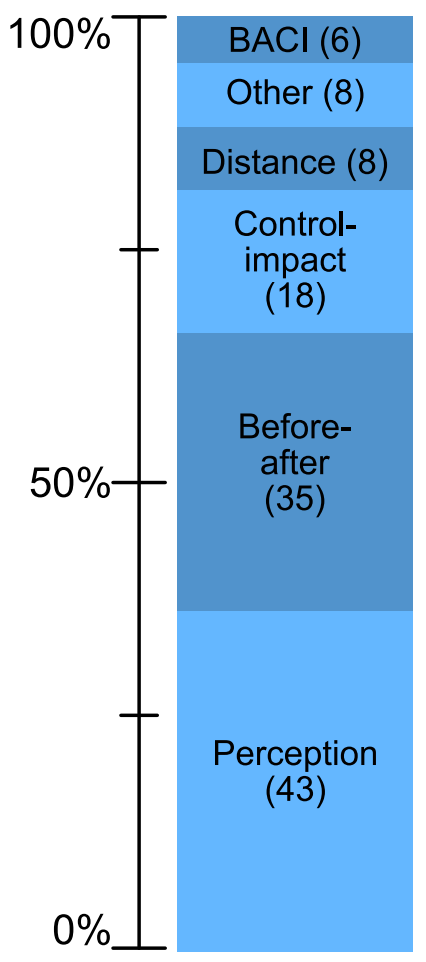

Study design

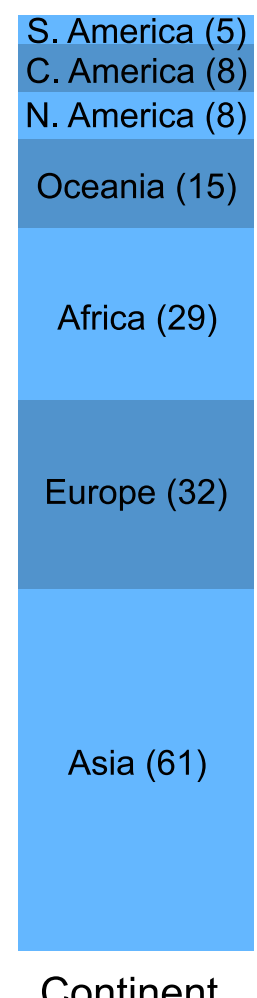

Continent

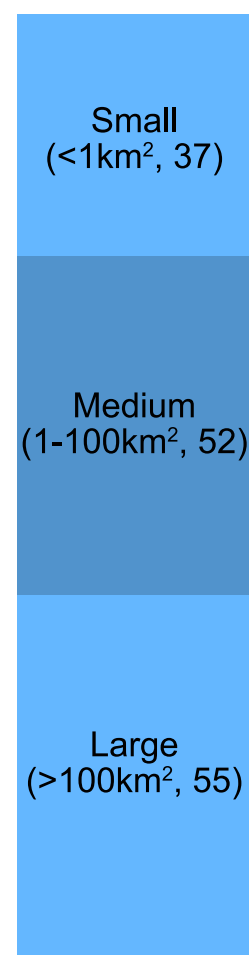

Size

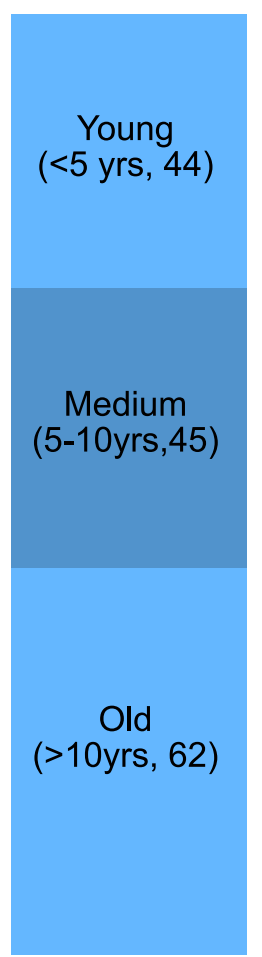

Age

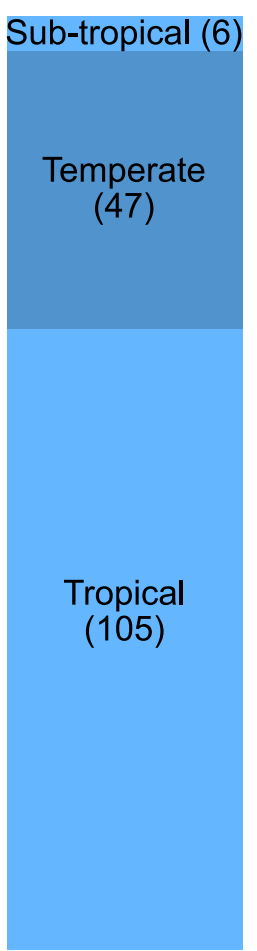

Ecosystem

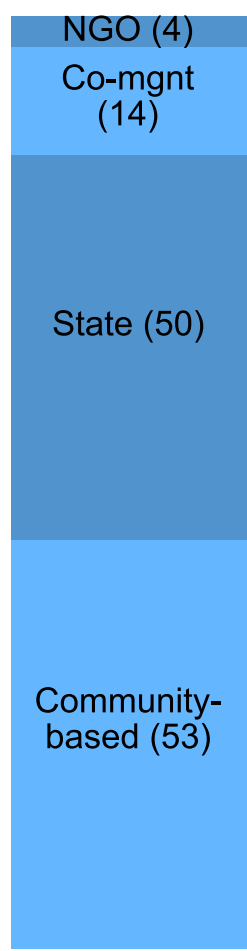

Governance 


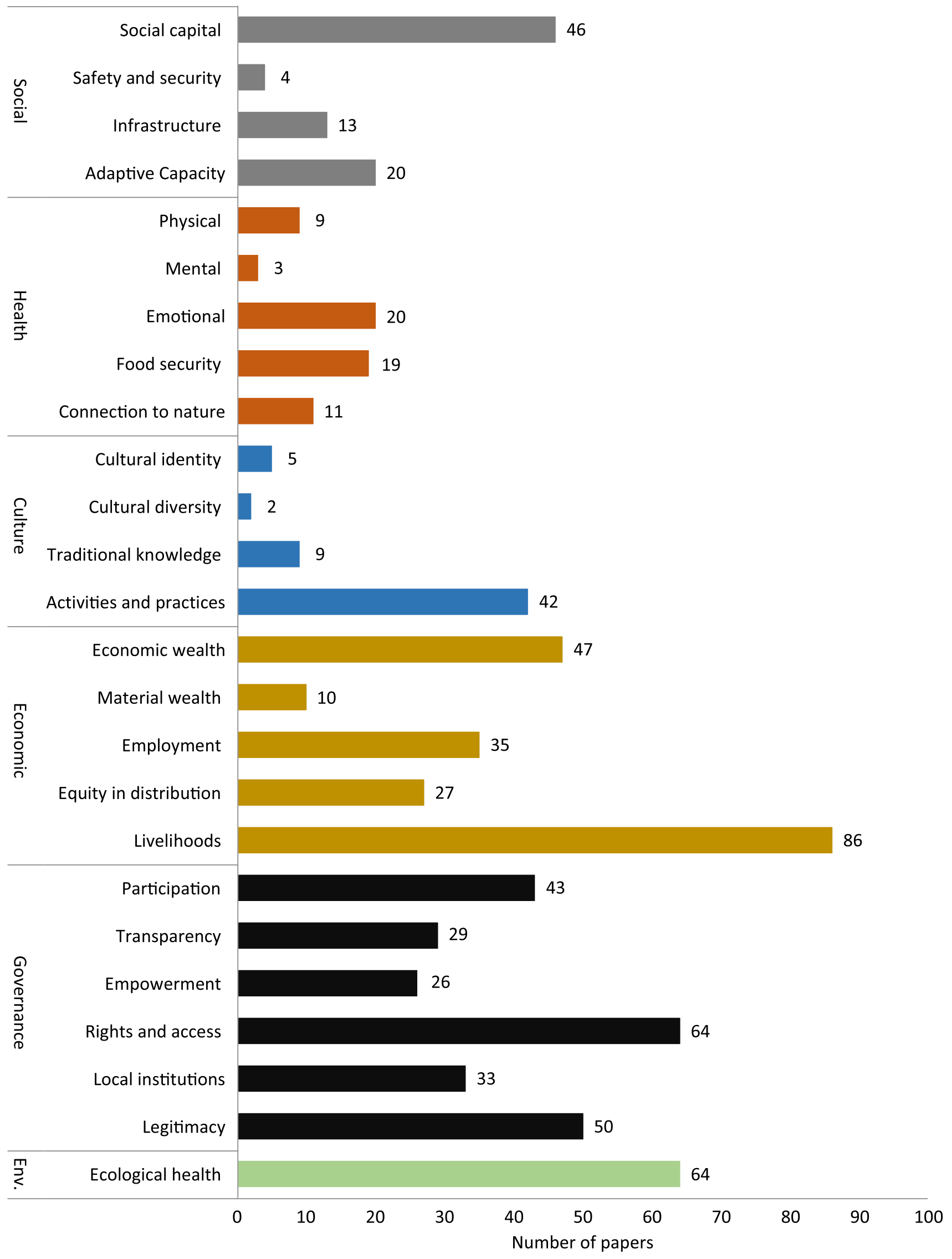




\section{Positive effects (\%) Negative effects (\%) Ambiguous effects (\%) Number of data points}

All combined

51

31

17

606

Number of users

44

34

22

59

Income

CPUE

Catches

Cost of fishing

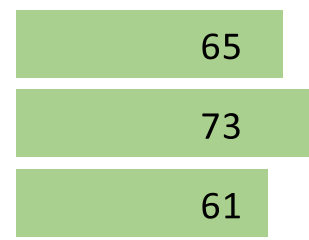

\begin{tabular}{|c|}
16 \\
11 \\
\hline 20 \\
\hline 100
\end{tabular}

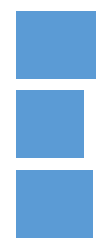

20

51

17

66

19

124

0

0

13

Resource control

58

34

8

38

Support

Spatial change

61

33

6

83

22

25

52

67

Conflict

Com. involvement
15

76
5

21
78

34 
